\title{
Every Voice Matters: The Importance of Advocacy
}

\author{
Amber J. Royea · Dolores J. Appl
}

Published online: 29 July 2009

(C) Springer Science+Business Media, LLC 2009

\begin{abstract}
Over the years parents, professionals, and politicians have come together to advocate on behalf of children's rights. Advocacy can occur individually, collectively, or a combination of both. Although some advocacy efforts are more successful than others, it is the process of the advocacy and voices behind it that matter most. In this guest editorial, the history of two major advocacy organizations and ideas for becoming an advocate are discussed.
\end{abstract}

\section{Keywords Advocacy}

How would you react if you overheard colleagues and administrators talking about "those special ed kids" or the "autistic child" or the "handicapped parent" who cannot access his child's classroom? The common thread among these examples is the focus on what is wrong with each person as opposed to who the individual is as a person. When you hear these types of politically incorrect statements, what do you do? Perhaps, you are unaware that such statements are inappropriate. Perhaps you are aware, but choose to ignore them. Or, you might act by modeling or suggesting the use of people-first language, which means referring to the person before using other descriptors (Moris 2003). What if you read an article in the newspaper or hear a newsperson use such language? Would you send an email or

A. J. Royea · D. J. Appl ( $₫)$

Early Childhood Special Education Program,

University of Maine at Farmington, 186 High Street,

Farmington, ME 04938, USA

e-mail: dappl@maine.edu

A. J. Royea

e-mail: amber.royea@gmail.com letter? If you take action, you are advocating for individuals who happen to have disabilities, but also have many abilities. They are people first and foremost; their disabilities do not define them!

Early childhood professionals frequently encounter issues that pertain to young children and families. Unlike saying or doing nothing when faced with inequities, advocates are risk takers who challenge the status quo. A person who advocates is substantially different from one who keeps silent and travels "the path of least resistance." Following a path of least resistance can result in a professional who is "immobilized throughout a career, stagnates, and loses rather than gains competence" (Jalongo 2002, p. 65). In this editorial, we define advocacy, discuss why it is a professional responsibility, provide some history behind two well-known advocacy groups, and describe basic advocacy skills.

Advocacy is telling or demonstrating something you know to someone you know in order to improve the quality of life for others (Mitchell and Philibert 2002; Zeitler 2007). Child advocacy is any individual or cooperative action that strives to enrich the lives of children, including challenging injustices and promoting overall welfare (Pithouse and Crowley 2007). In some instances, professionals may feel constrained in their advocacy efforts by their employer. However, advocacy is a professional responsibility (Mitchell and Philibert 2002) and, "if you do not take action, who will?" (LaRocco and Bruns 2005, p. 12).

Both the Division of Early Childhood (DEC) of the Council for Exceptional Children and the National Association for the Education of Young Children (NAEYC) provide codes of ethics with policies related to advocacy. DEC's code states that members should be committed to serve as advocates "for children with special needs and their families and for the professionals who serve them in 
our communities, working with those who make the policy and programmatic decisions that enhance or depreciate the quality of their lives" (Sandall et al. 2005, p. 296). NAEYC includes a supplemental document in their code of ethics, which is titled "Statement of Commitment" and has an item pertaining to advocacy. It states that each member should "serve as an advocate for children, their families, and their teachers in community and society" (NAEYC 2005, Statement of Commitment section, item 5). Therefore, advocacy is an essential responsibility of professionals working with young children and families.

Over the years parents, professionals, and politicians have come together to advocate on behalf of children's rights. They have advocated both individually and collectively in order to make changes they want to see in the world. The use of people-first language is one example. Other examples include efforts to ensure adequate health care coverage for children and families, proper educational services for children with and without disabilities, protection of children's safety and well-being, and funding to maintain high quality services and programs. Advocacy also pertains to efforts in support of sufficient funding and coverage for teachers, interventionists and other professionals who serve children and their families (Children's Defense Fund 2009; LaRocco and Bruns 2005; Zeitler 2007). Taking action as an individual person or as part of a group can have monumental effects in the lives of children, families, and the professionals serving them (Mitchell and Philibert 2002). There are organizations devoted to advocacy that can assist you in your efforts. Two highly influential groups in the history of child and family advocacy include the Children's Defense Fund (Children's Defense Fund 2009) and the Citizens' Committee for Children of New York (McDonald 1995).

The Children's Defense Fund (CDF) is a child advocacy organization, founded by Marian Wright Edelman in 1973 out of Washington, D.C. Their "mission is to ensure every child a Healthy Start, a Head Start, a Fair Start, a Safe Start and a Moral Start in life and successful passage to adulthood with the help of caring families and communities" (CDF 2009). Since its establishment in 1973, the Children's Defense Fund has been a pioneer in child advocacy by teaming with families, community members, politicians, and professionals nationwide. Accomplishments to which its members and supporters have contributed include separating children from adults in the jail system and pushing for Medicaid expenses to cover children and pregnant women in poverty. They have also helped to pass important legislation, such as the Juvenile Justice and Delinquency Prevention Act, the Adoption Assistance and Child Welfare Act, and the Education for All Handicapped Children Act (P.L. 94-142), which was the predecessor of the current Individuals with Disabilities Education Act (IDEA).
Additionally, in 1994 and 1995 the CDF helped defeat the Republican Party's "Contract with America" proposals that would have lead to significant cuts in income, health, foster care, and nutrition programs for American children (CDF 2009).

The Citizens' Committee for Children of New York (CCC), a nonprofit agency still in existence today, was also an early pioneer in child advocacy. Formed in 1944, and deeply rooted in the civil rights movement, the CCC's mission is to serve as a voice for children by ensuring that they have their basic needs met and have access to quality educational programs (Citizens' Committee for Children of New York Inc 2006). CCC strives to keep children safe through their efforts to adapt social and political policies (CCC 2006; McDonald 1995). Its members include people from many different facets of life in New York City, including parents, youth, policymakers, professionals, journalists, and other concerned citizens from all five boroughs. The diversity and comprehensiveness of its membership help ensure that its efforts resonate throughout the city (CCC 2006). Since its establishment, CCC has conducted an extensive amount of qualitative research on child well-being, facilitated community education programs, provided community members with newsletters and e-alerts, and consistently come together to reach out to policymakers and officials in order to pass budgets, legislations, and policies that best serve the children and families of New York City (CCC 2006; McDonald 1995).

Both of the advocacy organizations described above are effective because their efforts are shared and supported by many people at state, nation, and worldwide levels who promote children's rights and welfare. However, they did not start out that way. Their ambitions took years of planning and organization in order to develop a strong base of supporters. Pithouse and Crowley (2007) suggest that mainstreaming child advocacy through efforts that emphasize a focus on the real issues children face in our world, rather than adult agendas and desires, could lead to landmark changes in the future of advocacy. In order to be most effective, advocacy efforts require a genuine desire for change and efficient communication. Advocacy also involves building relationships with fellow advocates, as well as elected officials at the local, state, and national levels (LaRocco and Bruns 2005; Zeitler 2007).

Advocacy is a process that can be executed in several different ways. In a basic way, one might advocate by modeling people first language, such as "Mr. Jones is a parent who happens to use a wheelchair." Or, one might verbally express concerns. For instance, I (first author) recently heard an advertisement on the radio that failed to use people-first language. Even more distressing was that the ad was for an agency serving individuals with disabilities. I called and expressed my disappointment and, while 
it might be a coincidence, I have not heard the ad since. A more visible way to advocate on behalf of children and families is by writing, e-mailing, or phoning members of local or state legislature, Congress, or Senate. Others may choose to act by getting involved with their local school board, city council, and other committees, such as their local school's parent and teacher association (PTA) or executive boards of agencies that serve children and families (LaRocco and Bruns 2005; Zeitler 2007).

As professionals, we also have the responsibility to support parents in their role as advocates. Linda Nickerson is the parent of an adult child with developmental differences. During a recent interview she emphasized that parents can and do become activists on individual levels. They do so by building relationships with school personnel, professionals, and service providers in order to advocate for the rights and needs of children and families (Nickerson 2009).

No matter who you are or what you do, you can be involved in advocacy efforts at a personal, public, or private-sector level (Hyson 2008). Within local communities, states, and nationwide, there are multiple opportunities for individuals to become involved in interest groups and trainings. Simply becoming informed about public policy issues and sharing that information with friends, family, and colleagues can help spread the word about important matters affecting children and their families. Advocacy efforts can also ensure that people within the community make informed decisions when voting. You can let community members know where you stand on public policies, important issues, and political leaders by submitting letters to local or state newspapers or employee newsletters, wearing buttons or displaying bumper stickers on your car. Whatever steps you take, "It is the quality and power of individual actions that can make the difference" (LaRocco and Bruns 2005, p. 12).

You do not need to be an expert public speaker or political activist in order to advocate for changes in which you believe. You only need to have an understanding of the issues you wish to address and a willingness to share your beliefs with those around you (LaRocco and Bruns 2005; Zeitler 2007). However, Zeitler (2007) emphasizes the importance of "telling what you know from the heart" (p. 5). Advocates tend to be passionate about their causes and have certainly seen their share of triumphs and disappointments. Yet, no matter what the outcome of their efforts, it is the process of the advocacy and voices behind it that matters most. To increase the likelihood that others will listen to you, it is important to define your core message and frame the issues for your intended audience. When clear, concise messages are consistently used, you are more likely to engage others in your cause (Hyson 2008).

Now is the time to take steps in becoming an advocate or increasing your current advocacy efforts. Therefore, "challenge the status quo and strive to transform educational settings" (Jalongo 2002, p. 65). Rather than following the path of least resistance that can immobilize your career and cause you to stagnate, become an advocate and competent professional. Remember, every voice matters!

\section{References}

Children's Defense Fund. (2009). Who is CDF? Retrieved April 12, 2009 from http://www.childrensdefense.org/who-is-cdf/.

Citizens' Committee for Children of New York Inc. (2006). Who we are. Retrieved April 13, 2009 from http://www.cccnewyork.org/ whatwedo.html.

Hyson, M. (2008). Enthusiastic and engaged learners: Approaches to learning in the early childhood classroom. New York: Teachers College Press.

Jalongo, M. R. (2002). On behalf of children: "Taking a stand: It is rocket science”. Early Childhood Education Journal, 30, 65-66.

LaRocco, D. J., \& Bruns, D. A. (2005). Advocacy is only a phone call away: Strategies to make a difference on behalf of children and their families. Young Exceptional Children, 8(4), 11-18.

McDonald, M. J. (1995). The Citizens' Committee for Children of New York and the evolution of child advocacy (1945-1972). Child Welfare, 74(1), 283-304.

Mitchell, L. M., \& Philibert, D. B. (2002). Family, professional, and political advocacy: Rights and responsibilities. Young Exceptional Children, 5(4), 11-18.

Moris, S. L. (2003). The language of inclusion. Child Care plus+, 13(2), 1.

National Association for the Education of Young Children. (2005). Code of ethical conduct and statement of commitment. Retrieved July 18, 2009 from http://www.naeyc.org/positionstatements/ ethical_conduct.

Nickerson, L. (2009). Personal communication, March 14th. Reprinted with permission.

Pithouse, A., \& Crowley, A. (2007). Adults rule? Children advocacy and complaints to social services. Children and Society, 21, 201-213.

Sandall, S., Hemmeter, M. L., Smith, B. J., \& McLean, M. E. (2005). DEC recommended practices: A comprehensive guide for practical application. Longmont, CO: SoprisWest.

Zeitler, C. L. (2007). Justice matters. ACEI Focus on Pre-K \& K, 20(2), 1 . 